\title{
GMR
}

\section{Reference gene selection for gene expression studies in lily using quantitative real-time PCR}

\author{
M.F. Zhang, Q. Liu and G.X. Jia \\ Beijing Key Laboratory of Ornamental Plants Germplasm Innovation and \\ Molecular Breeding, National Engineering Research Center for Floriculture \\ and College of Landscape Architecture, Beijing Forestry University, Beijing, \\ China \\ Corresponding author: G.X. Jia \\ E-mail: gxjia@bjfu.edu.cn
}

Genet. Mol. Res. 15 (2): gmr.15027982

Received November 4, 2015

Accepted February 29, 2016

Published April 29, 2016

DOI http://dx.doi.org/10.4238/gmr.15027982

ABSTRACT. Quantitative real-time polymerase chain reaction (qRTPCR) is an important technology used to analyze gene-expression levels. Reference genes, which are assumed to be expressed consistently across various developmental stages and in different tissues, were selected for expression level analysis. Using digital gene expression technology, we selected nine reference genes (18S, EF, CYCOL, SAND, GAPDH, ACTIN, BHLH, TIP, and Clathrin) as candidate reference genes for further study. Using three different analysis methods (GeNorm, NormFinder, and BestKeeper), a total of 144 lily (Lilium x formolongi "Raizan 3") samples were analyzed. The samples were collected from four different tissues under various developmental stages. In addition, leaves treated with different plant hormones were collected and analyzed. The data showed that the stability of the nine reference genes differed among samples, but TIP, EF, Clathrin, and BHLH could be identified as the most stable genes overall. In addition, the relative expression level of $L F F T$ in different lily tissues with the competence to flower was also analyzed to verify the selected reference genes. This study constitutes an important source for selecting reference genes 
when analyzing the expression patterns of flowering time and floral development regulation genes in lily cultivars.

Key words: Lily; Reference genes; qRT-PCR; GeNorm; NormFinder; BestKeeper

\section{INTRODUCTION}

Quantitative real-time polymerase chain reaction (qRT-PCR) is a powerful tool for measuring gene expression and will be essential for disclosing mysterious plant developmental processes. With the increasing importance of gene-expression analysis in biological research, qRT-PCR has become a high-throughput method for accurate gene-expression profiling.

Typically, a reference gene is used as internal control. However, if the expression of the reference gene is not constant or is altered under different experiment conditions, it will not only become impossible to detect small changes in other genes' expression levels, but could also result in biologically incorrect results. As a result, the selection of suitable reference genes for specific experimental purposes is highly important. Theoretically, reference genes should be essential for the maintenance of cellular function and vitality, and should be stably expressed in tissues and cells. However, in practice, their expression levels depend on tissue types, developmental stages, organisms, and experimental conditions (Stürzenbaum and Kille, 2001; Yoo et al., 2009). Furthermore, to avoid genomic DNA amplification, reference genes should not be associated with any pseudogene and their stability should be equivalent to that of the target gene transcript (Iland et al., 2006).

There have been many reports on reference gene validation in various plants, such as rice (Jain et al., 2006), chickpea (Garg et al., 2010), soybean (Jian et al., 2008; Hu et al., 2009), tomato (Expósito-Rodríguez et al., 2008), chrysanthemum (Gu et al., 2011), and poplar (Gutierrez et al., 2008). The results illustrate that candidate reference genes may vary among species and even among different cultivars. For sweet potato cultivars, the reference genes $A C T$ ( $\beta$-actin) and TUB were selected as the most stable gene set in the Yulmi cultivar, but for cultivars Sinhwangmi, Sinzami, and Whitestar, the gene sets COX/TUB, PLD/RPL, and $C O X / U B I$, respectively, were better (Park et al., 2012). These genes also showed differences depending of tissue and treatment. The selection of reliable reference genes for gene-expression under abiotic stress in Gossypium hirsutum L. showed that the reference gene needed to be selected based on the specific condition. For example, under salt stress, $U B Q 7$ (ubiquitin), $G A P D H$ (glyceraldehyde-3-phosphate dehydrogenase), and $E F-1 a 8$ are better reference genes in the leaves, whereas TUA10, UBQ7, CYP1, GAPDH, and EF-1a8 were better in the roots. Under drought stress, $U B Q 7, E F-1 a 8, T U A 10$, and $G A P D H$ showed less gene-expression variation in both the leaves and the roots (Wang et al., 2013). For Vigna mungo, a high stability was obtained for $A C T$ and $E F-1 a$ during mungbean yellow mosaic India virus stress; $H 2 A, E F-1 a$, and $A C T$ were found to be most suitable under salinity stress experiments; and $T U B$ and $18 S$ (18S rRNA) during drought treatments (Kundu et al., 2013). Commonly known housekeeping genes like GAPDH, ACTB, and $18 S$ have been used in many expression studies for different tissues (Thellin et al., 1999; Bustin, 2000). Currently, many kinds of endogenous reference genes, such as tubulin (alpha- or beta-), ribosomal units (18S or $28 S \mathrm{r} R N A$ ), and $U B Q$ (Ito et al., 2006), are widely used to normalize data in gene-expression analyses. However, there were also many recent reports showing that not all well-known and frequently used reference 
genes are appropriate in qRT-PCR analysis due to their expression variability.

It is essential to evaluate the stability of candidate reference genes and many software packages have been developed to this end. Recently, several statistical analysis methods, such as GeNorm (Vandesompele et al., 2002), NormFinder (Andersen et al., 2004), and BestKeeper (Pfaffl et al., 2004), have been proposed for evaluating the expression stability of reference genes and selecting the most suitable reference genes. The GeNorm, NormFinder and BestKeeper use different mathematical algorithms to estimate the most suitable reference genes

Many reports state that different plant species have clearly defined reference genes for different organs and different environmental conditions. However, no systematic survey has determined such reference genes for the lily. As the molecular biological studies, especially those involving gene-expression, increases in the lily, qRT-PCR is being applied more frequently. Based on previous results in other species, a validation of several candidate reference genes in lily cultivars is essential. In the present study, digital gene-expression technology was used to analyze the different gene-expression levels in different tissues, development stages, and under different plant hormone treatments in the lily. Nine potential reference genes were selected as candidate genes, in this study. The performance of all these genes was analyzed in various tissues, at different developmental stages, as well as under different plant hormone treatments. Furthermore, GeNorm (Vandesompele et al., 2002), NormFinder (Andersen et al., 2004), and BestKeeper (Pfaffl et al., 2004) were applied, to determine the most suitable reference gene(s). To verify the usefulness of the selected reference genes, the expression pattern of $L f F T$, was analyzed in different tissues when the plants were competent to flower. To our knowledge, this study is the first attempt at evaluating suitable reference genes for use in qRT-PCR studies, while also quantifying transcripts expressed at different developmental stages, in different tissues, as well as under different hormone treatments in the lily. The present study will be of great benefit to future studies on gene-expression in the lily.

\section{MATERIAL AND METHODS}

\section{Plant material and sample collection}

In this experiment, the Lilium x formolongi "Raizan 3" cultivar was used. Bulbs were planted in a greenhouse under optimal cultivation conditions. During the cold storage time of the bulbs, bubs were collected weekly, adding up to a total of six times which noted as Bud-0, Bud-1, Bud-2, Bud-3, Bud-4, and Bud-5. From the time the bulbs were planted to the appearance of flower buds, we selected samples, including the apical meristems, stems, and leaves, every two weeks, totaling six times. Flower buds of lengths $1,1.5,2,2.5,3$, and $4 \mathrm{~cm}$ were selected for analysis.

The hormone treatments comprised exposure to salicylic acid (SA), methyl jasmonate (JA), and ethylene (ET), respectively. Plants were sprayed with a 150 and 200 $\mu \mathrm{M}$ solution of SA and JA, respectively. For the ET treatments, $1 \mathrm{~mL}$ was injected into the air of plants kept under a sealed 50-L plexiglas box on a laboratory bench. Leaves of treated plants were collected at 2, 6, 12, 24, 36, and $48 \mathrm{~h}$ after the chemical treatments and a Botrytis inoculation of leaves with visible traces of fungal spore inoculations was performed. After collection, all samples were immediately frozen in liquid nitrogen and stored at $-80^{\circ} \mathrm{C}$ until further analysis. 


\section{RNA extraction, quality control and cDNA synthesis}

A Total RNA Isolation System (Aidlab, Beijing, China) was employed following the manufacturer instructions. To investigate the RNA quality, a 1\% agarose gel electrophoresis was applied. The concentration was ascertained using a NanoDrop ND-1000 spectrophotometer (Wilmington, DE, USA) according to the standards, which were $1.8 \leq \mathrm{OD}_{260 / 280} \leq 2.2$ and $\mathrm{OD}_{260 / 230} \geq 1.8$. All samples were pretreated with an RNase-free DNase I (Promega, Madison, WI,USA) at $37^{\circ} \mathrm{C}$ for $30 \mathrm{~min}$, in order to eliminate any DNA contamination. The first strand cDNA was synthesized using the M-MLV reverse transcription system (Promega) following the manufacturer protocol (Fu et al., 2014). The cDNA was subsequently stored at $-20^{\circ} \mathrm{C}$ until further use.

\section{Selection of reference sequences}

In a preliminary study, an Illumina/Solexa library of lily "Sorbonne" was constructed (Zhang et al., 2015). In total, 39,636 unigenes were identified, 30,986 of these genes were annotated with BLASTX (data not shown). Nine reference genes were selected for geneexpression normalization among the samples from the different developmental stages, tissues, and hormone treatments.

\section{PCR primer design and test of amplification efficiency}

Primers were designed using Beacon designer software with melting temperatures $(\mathrm{Tm})$ of $54^{\circ}-60^{\circ} \mathrm{C}$, primer lengths ranging between 17 and $26 \mathrm{bp}$, and amplicon lengths of approximately $200 \mathrm{bp}$. The specific primer sequences are listed in Table 1 . The performance of the designed primers was tested by qRT-PCR. A serial dilution of pooled cDNA was used to generate a standard curve, which was then used to estimate the reaction efficiency of each primer pair. The mean quantification cycle $(\mathrm{Cq})$ values of each ten-fold dilution were plotted against the logarithm of the cDNA dilution factor.

Table 1. Reference gene primer sequences and amplicon characteristics in the lily.

\begin{tabular}{|c|c|c|c|c|c|c|c|c|}
\hline $\begin{array}{l}\begin{array}{l}\text { Gene } \\
\text { symbol }\end{array} \\
\end{array}$ & Full name & Cellular function & 5'-3' sequence (Forward/Reverse) & $\begin{array}{l}\text { Amplicon } \\
\text { size (bp) }\end{array}$ & $\begin{array}{l}\mathrm{Tm} \\
\left({ }^{\circ} \mathrm{C}\right)\end{array}$ & $\begin{array}{c}\text { PCR } \\
\text { efficiency } \\
(\%)\end{array}$ & $\begin{array}{c}\text { Regression } \\
\text { coefficient } \\
\left(\mathrm{R}^{2}\right)\end{array}$ & $\begin{array}{l}\text { Mean } \mathrm{Cq} \\
\text { value }\end{array}$ \\
\hline \multirow[t]{2}{*}{$18 \mathrm{~S}$} & 18 S ribosomal RNA & \begin{tabular}{|l|} 
Ribosome subunit \\
\end{tabular} & GCAGAATCCCGTGAACCAT & 143 & 54 & 106.7 & 0.998 & 20.09 \\
\hline & & & GCCAATCTCCGCATCCAT & & & & & \\
\hline \multirow[t]{2}{*}{$E F$} & EF-1a & \begin{tabular}{|l|} 
Eukaryotic elongation factor 1-alpha \\
\end{tabular} & GGCACTAACTCGCTCCTTCTG & 173 & 55 & 106.1 & 0.998 & 18.94 \\
\hline & & & $\begin{array}{l}\text { TTGGTAAGATGCTGGTGATTGGAT } \\
\end{array}$ & & & & & \\
\hline \multirow[t]{2}{*}{ CYCOL } & Cycolphilin A & Serine-threonine phosphatase inhibitor & ACCCTTGGGCAAGAACAACAGAA & 127 & 56 & 99.3 & 0.997 & 19.66 \\
\hline & & & GCAAAGGAGGTTGAGTTGGAGGAT & & & & & \\
\hline \multirow[t]{2}{*}{$S A N D$} & SAND family protein & Hypothetical proteins & CCAATACCCAGATGAGGAGACAAA & 178 & 54 & 105.4 & 0.992 & 22.73 \\
\hline & & & GGATTCGCATTGAGGCTGTTC & & & & & \\
\hline \multirow[t]{2}{*}{ GAPDH } & Glyceraldehyde-3-phosphate & $\begin{array}{l}\begin{array}{l}\text { Oxidoreductase in glycolysis and } \\
\text { gluconeogenesis }\end{array} \\
\end{array}$ & CACGGTCAGTGGAAGCACCATGAGAT & 180 & 60 & 97.6 & 0.995 & 17.33 \\
\hline & & & AGCAGCAGCCTTATCCTTGTCAGTGA & & & & & \\
\hline \multirow[t]{2}{*}{ ACTIN } & Beta actin & \begin{tabular}{|l|} 
Cytoskeletal structural protein \\
\end{tabular} & CCCATTGAGCACGGCATTGTC & 128 & 56 & 102.8 & 0.999 & 20.46 \\
\hline & & & GGATTGAGAGGAGCTTCGGTGAGA & & & & & \\
\hline \multirow[t]{2}{*}{ BHLH } & Basic helix-loop-helix & Transcription factor & CCAGCAGGTTGTCCTTGTG & 142 & 56 & 106.3 & 0.998 & 21.15 \\
\hline & & & TCCGTGATGAGAAGCAGAGG & & & & & \\
\hline \multirow[t]{2}{*}{$T I P$} & TIP41 family protein & \begin{tabular}{|l|} 
Tonoplast intrinsic proteins \\
\end{tabular} & CGAAGCCAGAAACGGAGAAGAAT & 192 & 55 & 107.9 & 0.998 & 20.94 \\
\hline & & & GGGTAGGGTGGATTGGGAAGA & & & & & \\
\hline Clathrin & Clathrin & \begin{tabular}{|l|} 
Clathrin adaptor complex \\
\end{tabular} & GATGAGATTCTGATTGCTGGTGAG & 103 & 55 & 93.0 & 0.999 & 20.80 \\
\hline & & & CCTGCTCTTTGGCTGTTTCC & & & & & \\
\hline
\end{tabular}




\section{qRT-PCR}

The qRT-PCR was performed on an optical 96-well plate with a Mini Opticon Realtime PCR System (Bio-Rad, Hercules, CA, USA) based on SYBR Premix Ex Taq (TaKaRa, Kusatsu, Shiga, Japan). The total reaction volume, $20 \mu \mathrm{L}$, contained $2 \mu \mathrm{L}$ template of each amplification primer $(10 \mu \mathrm{M}, 0.4 \mu \mathrm{L}), 2 \mathrm{X}$ SYBR Premix Ex Taq $(10 \mu \mathrm{L})$, and $7.2 \mu \mathrm{L} \mathrm{ddH}_{2} \mathrm{O}$. The following program was used for all PCRs: reactions: $95^{\circ} \mathrm{C}$ for $2 \mathrm{~min}, 40$ cycles of $95^{\circ} \mathrm{C}$ for $10 \mathrm{~s}$ and $15 \mathrm{~s}$ at the respective annealing temperatures, followed by $15 \mathrm{~s}$ at $72^{\circ} \mathrm{C}$. Melting curves were recorded after the 40th cycle by increasing the temperature stepwise by $0.5^{\circ} \mathrm{C}$ every $5 \mathrm{~s}$ from $65^{\circ}$ to $95^{\circ} \mathrm{C}$.

\section{Statistical analysis}

The data obtained for each sample was analyzed using the GeNorm (v. 3.4) (Vandesompele et al., 2002), NormFinder (v. 0.953) (Andersen et al., 2004), and BestKeeper programs, according to their respective protocols. The GeNorm algorithm calculates the average pairwise variations $(\mathrm{V})$ between a given gene and all other control genes. It is thus able to identify the two most stable reference genes or multiple combinations of various stable genes. This tool uses the principle that the expression ratio of two perfect reference genes should remain constant across different experimental treatments. GeNorm was also used to determine the optimal number of reference genes, to normalize the expression of target genes. This estimation is based on the variation between two normalization factors (NF; the geometric mean value of the best reference genes), with stepwise inclusions of less stable reference genes $\left(\mathrm{V}_{\mathrm{n}} / \mathrm{V}_{\mathrm{n}+1}\right)$ (Nakayama et al., 2014). The NormFinder algorithm is based on an analysis of variance model. This algorithm evaluates the total variation in the expression of the candidate genes using the sum of variance (Moraes et al., 2015). As for BestKeeper, raw data in the form of raw Cq values generated by the RT-PCR platform are input to the BestKeeper software are on excel, separately for HKGs and TGs. It determines the "optimal" HKGs by employing a pair-wise correlation analysis of all pairs of candidate genes and calculates the geometric mean of the "best" suited genes (Pfaffl et al., 2004).

\section{Normalization of $L f F T$}

LfFT was cloned from bulb buds of Lilium x formolongi "Raizan 3" in our laboratory. It was used as a target gene to verify the identified candidate reference genes in a qRT-PCR. The expression levels of LfFT in bulb buds, apical meristems, stems, and leaves of plants with competence to flower were analyzed using either the most stable reference gene, or a combination of reference genes as determined by GeNorm.

LfFT primer pairs (forward: 5'-AGCAACAGAGAGTTCACCAATG-3'; reverse: 5'-GTGTGTAAAGGGTCCTCATGTC-3') were used for qRT-PCR $\left(\mathrm{Tm}=54^{\circ} \mathrm{C}\right)$.

\section{RESULTS}

\section{Performance of the primers for each reference gene}

The stability of the nine candidate reference genes was examined across the different 
tissues at different developmental stages (Table 1). The results of agarose gel electrophoresis and the presence of a single melting curve peak demonstrated that all nine primer pairs amplified a single band of expected size from various cDNA templates. The correlation coefficients $\left(\mathrm{R}^{2}\right)$ ranged between 0.9920 and 0.9990 , and PCR amplification efficiencies ranging between 93.0 and $107.9 \%$ were obtained from the standard curves generated using the serial cDNA dilution.

\section{Expression levels of the reference genes}

The mean expression levels of the nine candidate reference genes presented as $\mathrm{Cq}$ values are shown in Table 1. The mean values of the reference genes ranged between 17.33 and 22.70, suggesting that these reference genes were expressed at different levels in the lily. As shown in Figure 1, GAPDH showed the highest expression level in all samples and the lowest $\mathrm{Cq}$ value (15.450). SAND presented the lowest expression level and the highest $\mathrm{Cq}$ value (29.835). In general, the expression levels of most genes ranged from 17.82 to 23.20. This indicates that none of the selected genes were expressed consistently in the different lily samples. ACTIN, $18 S$, and GAPDH, which are the most commonly used reference genes, showed great variability. The $\mathrm{Cq}$ values in these three genes ranged from 18.11-26.85, 15.9824.41, and 15.45-23.69, respectively. Hence, it is necessary to evaluate the reference genes for normalization under different experimental conditions.

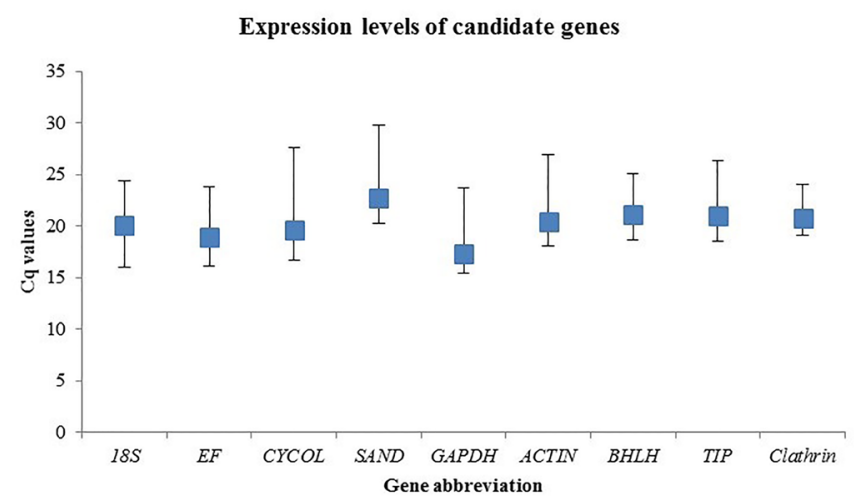

Figure 1. Expression levels of nine candidate reference genes across all samples of Lilium x formolongi "Raizan 3". The boxes represent mean $\mathrm{Cq}$ values, upper bars correspond to the maximum $\mathrm{Cq}$ values and lower bars represent the minimum Cq values.

\section{The stability of the reference genes}

In the present study, three methods were selected to analyze the gene stability data. A low value of $M$ generated from GeNorm, indicates more stable gene-expression, whereas a high $M$ value indicates a less stable gene-expression (Jin et al., 2013). Stably expressed genes have values below 1.5 (Vandesompele et al., 2002). The ranking orders, based on the $M$ value, are depicted in Figure 2. The $M$ values of four genes were below 1.5. In all samples, $E F$ and $B H L H$ were the most stably expressed genes with an $M$ value of 0.998 , followed by TIP and Clathrin. 18S and CYCOL were the least stable genes in all samples (Figure 2A). As far as the different tissues are concerned, $E F$ and TIP performed well with an $M$ value of 0.53 , whereas 
$18 S$ and $C Y C O L$ were considered unstable (Figure 2C). For the different development stages, $G A P D H$ and TIP were the most highly ranked with an $M$ value of 0.21 and $18 S$ and Clathrin were the least stable genes (Figure 2B). Under the different plant hormone treatments, $B H L H$ and Clathrin showed the greatest stability, followed closely by TIP. $18 S$ was the least stable housekeeping gene (Figure 2D).
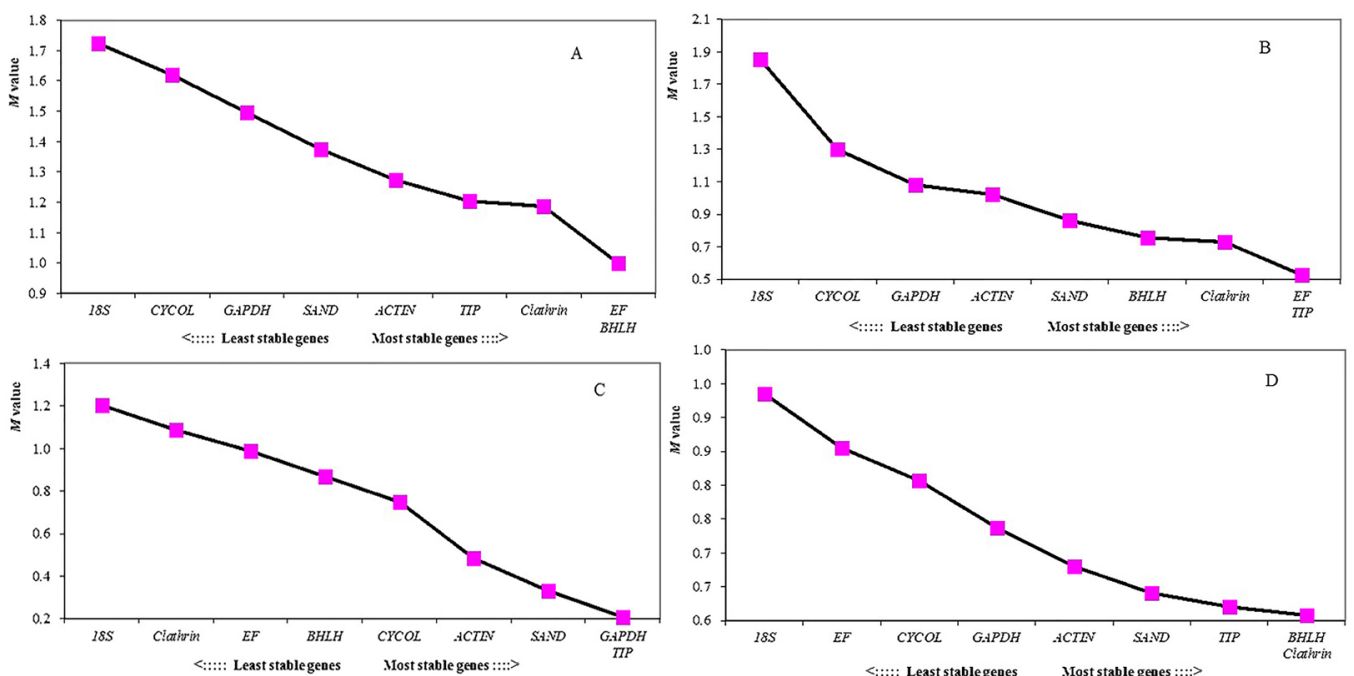

Figure 2. Average expression stability values $(M)$ of the candidate reference genes calculated using GeNorm. Note: The $M$ values are calculated following stepwise exclusion of the least stable gene across all treatment groups. The least stable genes are on the left and the most stable genes are on the right. (A) Total; (B) Developmental stages; (C) Different tissues; (D) Plant hormone treatments.

The pairwise variation $\left(\mathrm{V}_{\mathrm{n}} / \mathrm{V}_{\mathrm{n}+1}\right)$ was also calculated, to determine the optimal number of genes required for normalization. Overall, the $\mathrm{V}_{\mathrm{n}} / \mathrm{V}_{\mathrm{n}+1}$ values were higher than 0.15 under all experimental conditions, indicating that no optimal set of reference genes could be found (Figure 3). However, a threshold value of 0.15 may be too strict in some cases, considering that it is dependent on the number of genes and the type of samples tested (Kuijk et al., 2007; Silberberg et al., 2009; Fernandez et al., 2011). In addition, the decision of the number of reference genes is always a compromise between accuracy and cost. As a result, four stable reference genes were chosen because the inclusion of the fifth gene had no significant effect on the $\mathrm{V}$ value. In the case of the different tissues, two stable reference genes sufficed. In the different developmental stages, three stable reference genes were only just sufficient for normalization to analyze the gene-expression levels (with $\mathrm{V}$ value which is $0.169)$. Finally, for the hormone treatments, three genes were sufficient for normalization (with V value, which is 0.140 ).

The stability of reference genes was re-analyzed using NormFinder (Table 2). Genes were then ranked according to their stability under different experimental conditions through calculation of the NF. The ranking order generated by this method was slightly different from that found by GeNorm (Table 2). TIP was found to be the most stable gene for all samples, developmental stages, and tissues. Following TIP, was Clathrin and SAND. For plant hormone treatments, Clathrin was the most stable gene. In both the different tissues and the different 
development stages, the best combination of two genes was TIP and Clathrin, however, for the plant hormone treatment, the best combination was $S A N D$ and $G A P D H$.

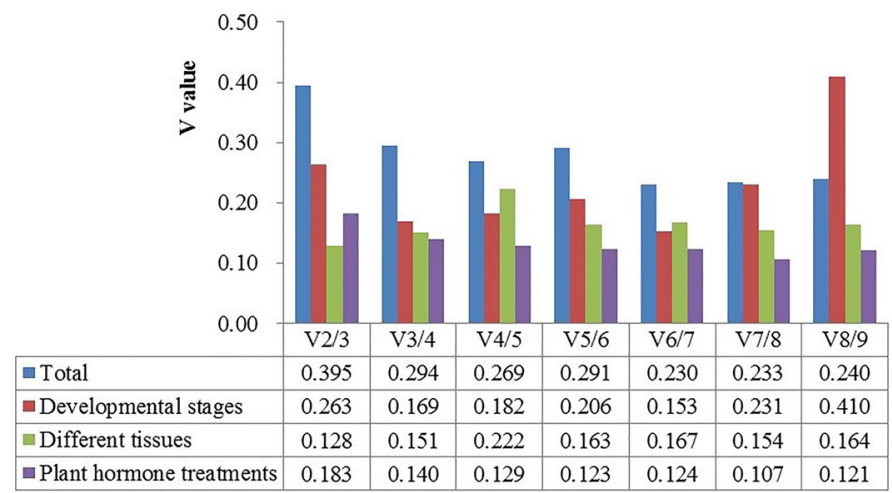

Figure 3. Pairwise variation (V) of the candidate reference genes calculated using GeNorm. Note: The V value indicates the optimal number of reference genes required for effective normalization. The $\mathrm{V}$ value was analyzed between the normalization factors $\mathrm{V}_{\mathrm{n}}$ and $\mathrm{V}_{\mathrm{n}+1}$, sing GeNorm.

Table 2. Ranking of reference genes and their expression stability values (NF) calculated using NormFinder.

\begin{tabular}{l|l|c|l|c|l|l|l|l}
\hline \multirow{2}{*}{ Ranking order } & \multicolumn{3}{|c|}{ Total } & \multicolumn{2}{c|}{ Developmental stages } & \multicolumn{2}{c|}{ Tissues } & \multicolumn{2}{c}{ Hormone treatments } \\
\cline { 2 - 9 } & Gene name & NF & Gene name & NF & Gene name & NF & Gene name & NF \\
\hline 1 & TIP & 0.455 & TIP & 0.192 & TIP & 0.417 & Clathrin & 0.239 \\
\hline 2 & Clathrin & 0.621 & Clathrin & 0.260 & SAND & 0.445 & BHLH & 0.248 \\
\hline 3 & ACTIN & 0.679 & SAND & 0.264 & GAPDH & 0.548 & TIP & 0.270 \\
\hline 4 & EF & 0.742 & GAPDH & 0.294 & ACTIN & 0.555 & SAND & 0.310 \\
\hline 5 & BHLH & 0.819 & ACTIN & 0.316 & Clathrin & 0.577 & ACTIN & 0.331 \\
\hline 6 & GAPDH & 0.872 & EF & 0.398 & EF & 0.650 & GAPDH & 0.336 \\
\hline 7 & SAND & 0.922 & BHLH & 0.429 & $18 S$ & 0.759 & EF & 0.364 \\
\hline 8 & $18 S$ & 1.208 & CYCOL & 0.521 & BHLH & 0.840 & CYCOL & 0.494 \\
\hline 9 & CYCOL & 1.209 & $18 S$ & 0.637 & CYCOL & 0.882 & $18 S$ & 0.560 \\
\hline
\end{tabular}

The stability of the reference genes was also analyzed using BestKeeper (Table 3). According to the $\mathrm{Cq}$ variation, Clathrin was the most stable gene both overall and for the developmental stage analysis. CYCOL was the most suitable HKG for different tissues followed by Clathrin. Contrasting with the results from all other analyses, for the plant hormone treatment, $B H L H$ was found to be the most stable gene.

As can be seen in Table 3, the results from the three different analysis methods showed slight differences. TIP was the most stable gene for the developmental stages and different tissues, according to GeNorm and NormFinder. In the case of the plant hormone treatments, the results indicated that $B H L H$ was the most suitable reference gene for analysis. The BestKeeper revealed that Clathrin was the most stable gene overall as well as for the developmental stage samples. There was some variation among the three methods, but in summary, TIP, EF, Clathrin, and $B H L H$ were identified as the top four reference genes for future study.

\section{Reference gene validation}

The reference gene validation was performed using the four most stable genes calculated by GeNorm (TIP, EF, Clathrin, and BHLH) as the internal control. The relative 
expression levels of the different tissues, including the stem, leaf, meristem, and bud, are shown in Figure 4. Similar expression patterns were found. When normalized using the ACTIN gene, which is the most commonly used reference gene, the expression pattern was slightly altered (Figure 4A-E). The $L f F T$ expression level of Bud-5 was the highest, differing from all other reference gene combinations. The expression pattern of $L f F T$ was entirely different when normalized with $18 \mathrm{~S}$, which was the least stable gene in the ranking order generated by three methods (Figure 4E). The expression level values ranged from 0.03-90.12. Using $18 S$ as the reference gene, the highest expression levels were found for bud-5 and meristem-4, which are quite different.

Table 3. Gene ranking according to the GeNorm, NormFinder, and BestKeeper calculations.

\begin{tabular}{|c|c|c|c|c|}
\hline \multirow[t]{2}{*}{ Ranking order } & \multicolumn{4}{|l|}{ GeNorm } \\
\hline & Total & Developmental stages & Tissues & Hormone treatments \\
\hline 1 & $E F$ & TIP & $T I P$ & BHLH \\
\hline 2 & BHLH & GAPDH & $E F$ & Clathrin \\
\hline 3 & Clathrin & SAND & Clathrin & $T I P$ \\
\hline 4 & $T I P$ & ACTIN & BHLH & $S A N D$ \\
\hline 5 & $A C T I N$ & CYCOL & SAND & $A C T I N$ \\
\hline 6 & SAND & BHLH & $A C T I N$ & GAPDH \\
\hline 7 & $G A P D H$ & $E F$ & $G A P D H$ & CYCOL \\
\hline 8 & CYCOL & Clathrin & CYCOL & $E F$ \\
\hline 9 & $18 S$ & $18 S$ & $18 S$ & $18 S$ \\
\hline \multirow[t]{2}{*}{ Ranking order } & \multicolumn{4}{|c|}{ NormFinder } \\
\hline & Total & Developmental stages & Tissues & Hormone treatments \\
\hline 1 & TIP & $T I P$ & TIP & Clathrin \\
\hline 2 & Clathrin & Clathrin & SAND & $B H L H$ \\
\hline 3 & ACTIN & SAND & GAPDH & TIP \\
\hline 4 & $E F$ & GAPDH & $A C T I N$ & SAND \\
\hline 5 & BHLH & $A C T I N$ & Clathrin & $A C T I N$ \\
\hline 6 & GAPDH & $E F$ & $E F$ & GAPDH \\
\hline 7 & SAND & BHLH & $18 \mathrm{~S}$ & $E F$ \\
\hline 8 & $18 S$ & CYCOL & $B H L H$ & CYCOL \\
\hline 9 & CYCOL & $18 S$ & CYCOL & $18 S$ \\
\hline \multirow[t]{2}{*}{ Ranking order } & \multicolumn{4}{|c|}{ BestKeeper } \\
\hline & Total & Developmental stages & Tissues & Hormone treatments \\
\hline 1 & Clathrin & Clathrin & CYCOL & BHLH \\
\hline 2 & TIP & BHLH & Clathrin & $E F$ \\
\hline 3 & BHLH & $E F$ & $B H L H$ & SAND \\
\hline 4 & $E F$ & $T I P$ & $A C T I N$ & GAPDH \\
\hline 5 & SAND & SAND & TIP & TIP41 \\
\hline 6 & $A C T I N$ & $A C T I N$ & $18 S$ & CYCOL \\
\hline 7 & GAPDH & GAPDH & GAPDH & $A C T I N$ \\
\hline 8 & $18 S$ & CYCOL & SAND & Clathrin \\
\hline 9 & CYCOL & $18 S$ & $E F$ & $18 S$ \\
\hline
\end{tabular}

\section{DISCUSSION}

qRT-PCR has emerged as a powerful tool for gene-expression analysis, especially with respect to sensitivity and specificity (Artico et al., 2010). The ideal reference genes should be stably expressed under all experimental conditions and be independent of organs, tissues, developmental stages, and treatments (Huggett et al., 2005). A systematic verification of the most suitable reference gene for specific experimental conditions is extremely important for gene-expression studies using qRT-PCR. 

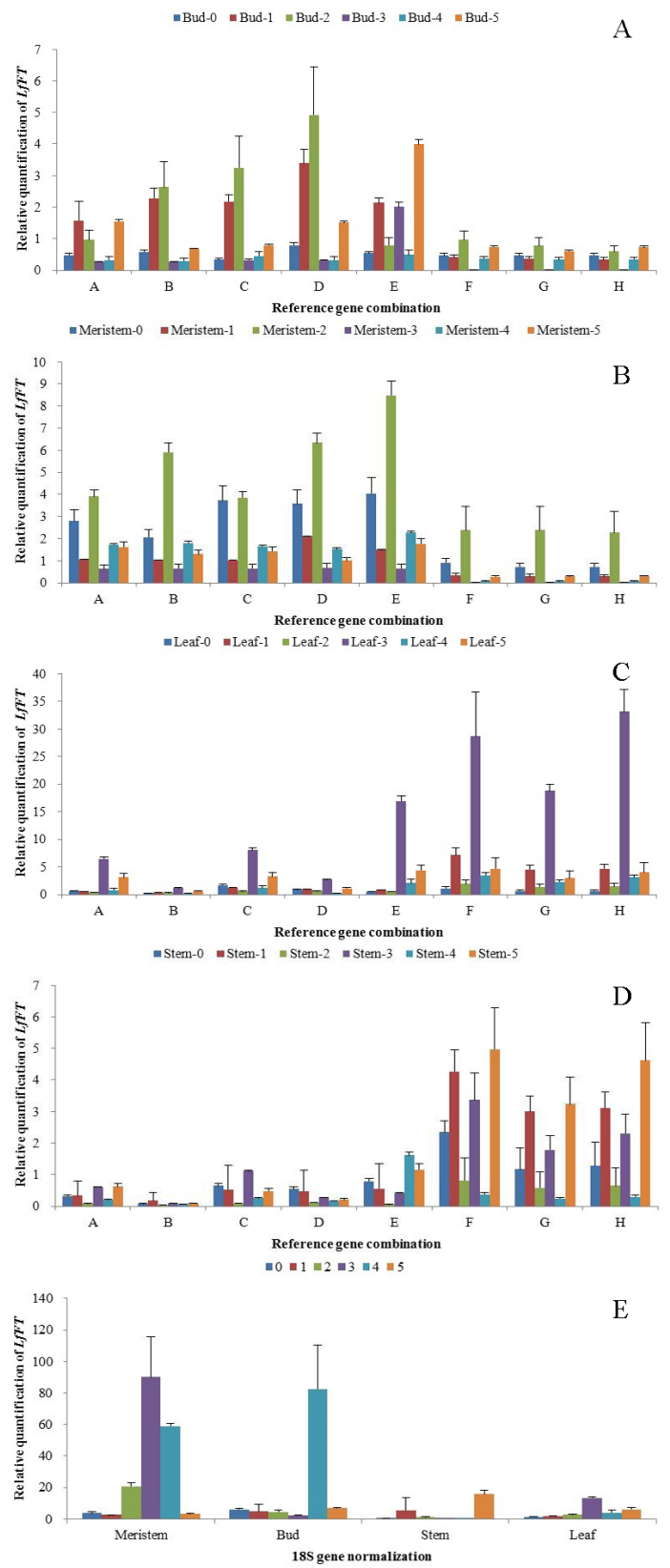

Figure 4. Relative quantification of $L f F T$ expression in different plant tissues with competence to flower, using validated reference genes for normalization. The reference genes and gene combinations used were A: TIP; B: Clathrin; C: EF; D: BHLH; E: ACTIN; F: EF and BHLH; G: EF, BHLH, and Clathrin; H: TIP, EF, BHLH, and Clathrin. Bars indicate the standard deviation of three technical replicates. A. Relative quantification of $L f F T$ expression in bud tissue; B. Relative quantification of $L f F T$ expression in meristem tissue; C. Relative quantification of $L f F T$ expression in leaf tissue; D. Relative quantification of $L f F T$ expression in stem tissue; E. Relative quantification of $L f F T$ expression with $18 S$ as reference gene. 
In the present study, the stability of nine reference genes in various tissues during different developmental stages and plant hormone treatments were analyzed. This is the first systematic study on expression stability of reference genes across such a large number of tissue samples from Lilium x formolongi. Based on the results presented here, of the nine candidate genes, $18 S, C Y C O L$, and GAPDH performed poorly. These results agree with those found in other studies (Bevitori et al., 2014). In contrast, TIP, EF, Clathrin and BHLH were good candidates for normalization in Lilium $x$ formolongi across all samples. While for rice under salt stress, the results were different that TIP, EF, Clathrin and BHLH were not suitable as candidate reference genes (Moraes et al., 2015).

However, traditional reference genes, such as the $A C T$ gene family, which is involved in many basic processes, are considered to be reliable reference genes for the purposes of plant flowering studies (Hong et al., 2008). According to two studies in soybean, it was revealed that $A C T 11$ was the most stably expressed gene under different photoperiodic treatments (Jian et al., 2008; Hu et al., 2009). In contrast to the results obtained for soybean, ACTIN performed poorly in the present study. $18 S$ is another widely used reference gene. For Lilium formosanum, Volvox carteri, and Solanum melongena, $18 S$ displays the most stable expression among samples both from different developmental stages and different stress treatments. However, in our study, $18 S$ performed poorly, which was similar to the results obtained in papaya (Zhu et al., 2012).

Compared with traditional reference genes, new reference genes, such as TIP41 (encoding TIP41-like family protein) and $S A N D$ (encoding SAND family protein) were expressed more stably during different developmental stages in tomatoes (Expósito-Rodríguez et al., 2008). TIP and Clathrin were identified as the most stable reference genes in five different experimental sets tested in Brassica juncea (Chandna et al., 2012) and has similar and stable transcription levels across Brassica crops (Chen et al., 2010). Previous studies on the selection of reference genes in tomato, Fagopyrum esculentum developmental stages, and soybean under varied light regimes (Expósito-Rodríguez et al., 2008; Hu et al., 2009; Demidenko et al., 2011) also identified TIP as the most stable reference gene for vegetative samples. In previous studies, Clathrin has also been identified as the best candidate for normalization (ExpósitoRodríguez et al., 2008; Obrero et al., 2011).

Another gene, $E F$, was found to be stably expressed in the present study, which was consistent with studies in soybean (Jian et al., 2008; Hu et al., 2009) and rice (Jain et al., 2006). Compared with $E F$, Clathrin expressed stably to some extent. It was highly stable under the different plant hormone treatments, but was unstable in different tissues and at different developmental stages. This result is consistent with the results from the different tissues/organs and developmental stages of tomatoes (Expósito-Rodríguez et al., 2008). $S A N D$ yielded low $M$ values in the different tissues and during the developmental process of Lilium x formolongi, consistent with the results in both petunias (Mallona et al., 2010) and tomatoes (Expósito-Rodríguez et al., 2008) at different developmental stages. TIP was found to be expressed consistently during different developmental stages in tomatoes (ExpósitoRodríguez et al., 2008) and Arabidopsis (Czechowski et al., 2005), and also yielded high $M$ values in all our experiments. Hence, we should choose reference genes that are suitable for normalization according to different experimental conditions.

Although qRT-PCR has been widely used over the past few years, normalization of reference genes still attracts some criticism. For example, there is no consensus concerning which algorithm should be applied to evaluate the stability of gene-expression. Different 
statistical methods based on different principles yield potentially contradictory results even when based on the same data. Among the studies using both GeNorm and NormFinder for normalization, some have shown minor differences between these methods, in terms of evaluating the best sets of reference genes in perennial ryegrass (Lee et al., 2010) and rice (Jain, 2009). Others have reported substantial differences between the two methods in longan (Lin and Lai, 2010) and rubber tree (Li et al., 2011). In addition, Andersen et al. (2004) noted that GeNorm may be insensitive to co-regulated reference genes. The inconsistencies between these two methods are expected because they are based on distinct statistical algorithms. In the current study, three methods were used to analyze the data to reduce the risk of inconsistent results. Although the gene stability rankings, GeNorm and NormFinder, were not identical, the top four candidate reference genes were quite similar. In accordance with previous reports (Vandesompele et al., 2002; Garcia-Crespo et al., 2005), as well as the results in the present study, we recommend the use of more than one reference gene to compensate for variation in tested samples.

\section{Conflicts of interest}

The authors declare no conflict of interest.

\section{ACKNOWLEDGMENTS}

Research supported by the National Natural Science Foundation (\#31470106) and the China Postdoctoral Science Foundation funded project (\#2015M581003).

\section{REFERENCES}

Andersen CL, Jensen JL and Ørntoft TF (2004). Normalization of real-time quantitative reverse transcription-PCR data: a model-based variance estimation approach to identify genes suited for normalization, applied to bladder and colon cancer data sets. Cancer Res. 64: 5245-5250. http://dx.doi.org/10.1158/0008-5472.CAN-04-0496

Artico S, Nardeli SM, Brilhante O, Grossi-de-Sa MF, et al. (2010). Identification and evaluation of new reference genes in Gossypium hirsutum for accurate normalization of real-time quantitative RT-PCR data. BMC Plant Biol. 10: 49. http://dx.doi.org/10.1186/1471-2229-10-49

Bevitori R, Oliveira MB, Grossi-de-Sá MF, Lanna AC, et al. (2014). Selection of optimized candidate reference genes for qRT-PCR normalization in rice (Oryza sativa L.) during Magnaporthe oryzae infection and drought. Genet. Mol. Res. 13: 9795-9805.http://dx.doi.org/10.4238/2014.November.27.7

Bustin SA (2000). Absolute quantification of mRNA using real-time reverse transcription polymerase chain reaction assays. J. Mol. Endocrinol. 25: 169-193. http://dx.doi.org/10.1677/jme.0.0250169

Chandna R, Augustine R and Bisht NC (2012). Evaluation of candidate reference genes for gene expression normalization in Brassica juncea using real time quantitative RT-PCR. PLoS One 7: e36918. http://dx.doi.org/10.1371/journal. pone. 0036918

Chen X, Truksa M, Shah S and Weselake RJ (2010). A survey of quantitative real-time polymerase chain reaction internal reference genes for expression studies in Brassica napus. Anal. Biochem. 405: 138-140. http://dx.doi.org/10.1016/j. ab.2010.05.032

Czechowski T, Stitt M, Altmann T, Udvardi MK, et al. (2005). Genome-wide identification and testing of superior reference genes for transcript normalization in Arabidopsis. Plant Physiol. 139: 5-17.http://dx.doi.org/10.1104/pp.105.063743

Demidenko NV, Logacheva MD and Penin AA (2011). Selection and validation of reference genes for quantitative realtime PCR in buckwheat (Fagopyrum esculentum) based on transcriptome sequence data. PLoS One 6: e19434.http:// dx.doi.org/10.1371/journal.pone.0019434

Expósito-Rodríguez M, Borges AA, Borges-Pérez A and Pérez JA (2008). Selection of internal control genes for quantitative real-time RT-PCR studies during tomato development process. BMC Plant Biol. 8: 131.http://dx.doi. org/10.1186/1471-2229-8-131 
Fernandez P, Di Rienzo JA, Moschen S, Dosio GA, et al. (2011). Comparison of predictive methods and biological validation for qPCR reference genes in sunflower leaf senescence transcript analysis. Plant Cell Rep. 30: 63-74. http://dx.doi.org/10.1007/s00299-010-0944-3

Fu J, Yang L and Dai S (2014). Conservation of Arabidopsis thaliana circadian clock genes in Chrysanthemum lavandulifolium. Plant Physiol. Biochem. 80: 337-347.http://dx.doi.org/10.1016/j.plaphy.2014.04.001

Garcia-Crespo D, Juste RA and Hurtado A (2005). Selection of ovine housekeeping genes for normalisation by real-time RT-PCR; analysis of PrP gene expression and genetic susceptibility to scrapie. BMC Vet. Res. 1: 3. http://dx.doi. org/10.1186/1746-6148-1-3

Garg R, Sahoo A, Tyagi AK and Jain M (2010). Validation of internal control genes for quantitative gene expression studies in chickpea (Cicer arietinum L.). Biochem. Biophys. Res. Commun. 396: 283-288. http://dx.doi.org/10.1016/j. bbrc.2010.04.079

Gu C, Chen S, Liu Z, Shan H, et al. (2011). Reference gene selection for quantitative real-time PCR in Chrysanthemum subjected to biotic and abiotic stress. Mol. Biotechnol. 49: 192-197. http://dx.doi.org/10.1007/s12033-011-9394-6

Gutierrez L, Mauriat M, Guénin S, Pelloux J, et al. (2008). The lack of a systematic validation of reference genes: a serious pitfall undervalued in reverse transcription-polymerase chain reaction (RT-PCR) analysis in plants. Plant Biotechnol. J. 6: 609-618. http://dx.doi.org/10.1111/j.1467-7652.2008.00346.x

Hong SY, Seo PJ, Yang MS, Xiang F, et al. (2008). Exploring valid reference genes for gene expression studies in Brachypodium distachyon by real-time PCR. BMC Plant Biol. 8: 112.http://dx.doi.org/10.1186/1471-2229-8-112

$\mathrm{Hu}$ R, Fan C, Li H, Zhang Q, et al. (2009). Evaluation of putative reference genes for gene expression normalization in soybean by quantitative real-time RT-PCR. BMC Mol. Biol. 10: 93. http://dx.doi.org/10.1186/1471-2199-10-93

Huggett J, Dheda K, Bustin S and Zumla A (2005). Real-time RT-PCR normalisation; strategies and considerations. Genes Immun. 6: 279-284. http://dx.doi.org/10.1038/sj.gene.6364190

Iland H, Hertzberg M and Marlton P (2006). Myeloid Leukemia: Methods and Protocols. Springer Sci. Bus. Med. 125.

Ito Y, Katsura K, Maruyama K, Taji T, et al. (2006). Functional analysis of rice DREB1/CBF-type transcription factors involved in cold-responsive gene expression in transgenic rice. Plant Cell Physiol. 47: 141-153. http://dx.doi. org $/ 10.1093 / \mathrm{pcp} / \mathrm{pci} 230$

Jain M (2009). Genome-wide identification of novel internal control genes for normalization of gene expression during various stages of development in rice. Plant Sci. 176: 702-706. http://dx.doi.org/10.1016/j.plantsci.2009.02.001

Jain M, Nijhawan A, Tyagi AK and Khurana JP (2006). Validation of housekeeping genes as internal control for studying gene expression in rice by quantitative real-time PCR. Biochem. Biophys. Res. Commun. 345: 646-651. http://dx.doi. org/10.1016/j.bbrc.2006.04.140

Jian B, Liu B, Bi Y, Hou W, et al. (2008). Validation of internal control for gene expression study in soybean by quantitative real-time PCR. BMC Mol. Biol. 9: 59.http://dx.doi.org/10.1186/1471-2199-9-59

Jin X, Fu J, Dai S, Sun Y, et al. (2013). Reference gene selection for qPCR analysis in cineraria developing flowers. Sci. Hortic. (Amsterdam) 153: 64-70. http://dx.doi.org/10.1016/j.scienta.2013.01.023

Kuijk EW, du Puy L, van Tol HTA, Haagsman HP, et al. (2007). Validation of reference genes for quantitative RT-PCR studies in porcine oocytes and preimplantation embryos. BMC Dev. Biol. 7: 58. http://dx.doi.org/10.1186/1471$\underline{213 X-7-58}$

Kundu A, Patel A and Pal A (2013). Defining reference genes for qPCR normalization to study biotic and abiotic stress responses in Vigna mungo. Plant Cell Rep. 32: 1647-1658. http://dx.doi.org/10.1007/s00299-013-1478-2

Lee JM, Roche JR, Donaghy DJ, Thrush A, et al. (2010). Validation of reference genes for quantitative RT-PCR studies of gene expression in perennial ryegrass (Lolium perenne L.). BMC Mol. Biol. 11: 8. http://dx.doi.org/10.1186/1471$\underline{2199-11-8}$

Li H, Qin Y, Xiao X and Tang C (2011). Screening of valid reference genes for real-time RT-PCR data normalization in Hevea brasiliensis and expression validation of a sucrose transporter gene HbSUT3. Plant Sci. 181: 132-139. http:// dx.doi.org/10.1016/j.plantsci.2011.04.014

Lin YL and Lai ZX (2010). Reference gene selection for qPCR analysis during somatic embryogenesis in longan tree. Plant Sci. 178: 359-365. http://dx.doi.org/10.1016/j.plantsci.2010.02.005

Mallona I, Lischewski S, Weiss J, Hause B, et al. (2010). Validation of reference genes for quantitative real-time PCR during leaf and flower development in Petunia hybrida. BMC Plant Biol. 10: 4. http://dx.doi.org/10.1186/1471-2229-10-4

Moraes GP, Benitez LC, do Amaral MN, Vighi IL, et al. (2015). Evaluation of reference genes for RT-qPCR studies in the leaves of rice seedlings under salt stress. Genet. Mol. Res. 14: 2384-2398. http://dx.doi.org/10.4238/2015. March.27.24

Nakayama TJ, Rodrigues FA, Neumaier N, Marcelino-Guimarães FC, et al. (2014). Reference genes for quantitative realtime polymerase chain reaction studies in soybean plants under hypoxic conditions. Genet. Mol. Res. 13: 860-871. http://dx.doi.org/10.4238/2014.February.13.4 
Obrero A, Die JV, Román B, Gómez P, et al. (2011). Selection of reference genes for gene expression studies in zucchini (Cucurbita pepo) using qPCR. J. Agric. Food Chem. 59: 5402-5411. http://dx.doi.org/10.1021/jf200689r

Park SC, Kim YH, Ji CY, Park S, et al. (2012). Stable internal reference genes for the normalization of real-time PCR in different sweetpotato cultivars subjected to abiotic stress conditions. PLoS One 7: e51502.http://dx.doi.org/10.1371/ journal.pone.0051502

Pfaffl MW, Tichopad A, Prgomet C and Neuvians TP (2004). Determination of stable housekeeping genes, differentially regulated target genes and sample integrity: BestKeeper--Excel-based tool using pair-wise correlations. Biotechnol. Lett. 26: 509-515.http://dx.doi.org/10.1023/B:BILE.0000019559.84305.47

Silberberg G, Baruch K and Navon R (2009). Detection of stable reference genes for real-time PCR analysis in schizophrenia and bipolar disorder. Anal. Biochem. 391: 91-97.http://dx.doi.org/10.1016/j.ab.2009.05.026

Stürzenbaum SR and Kille P (2001). Control genes in quantitative molecular biological techniques: the variability of invariance. Comp. Biochem. Physiol. B Biochem. Mol. Biol. 130: 281-289. http://dx.doi.org/10.1016/S10964959(01)00440-7

Thellin O, Zorzi W, Lakaye B, De Borman B, et al. (1999). Housekeeping genes as internal standards: use and limits. $J$. Biotechnol. 75: 291-295. http://dx.doi.org/10.1016/S0168-1656(99)00163-7

Vandesompele J, De Preter K, Pattyn F, Poppe B, et al. (2002). Accurate normalization of real-time quantitative RT-PCR data by geometric averaging of multiple internal control genes. Genome Biol. 3: RESEARCH0034.

Wang M, Wang Q and Zhang B (2013). Evaluation and selection of reliable reference genes for gene expression under abiotic stress in cotton (Gossypium hirsutum L.). Gene 530: 44-50. http://dx.doi.org/10.1016/j.gene.2013.07.084

Yoo WG, Kim TI, Li S, Kwon OS, et al. (2009). Reference genes for quantitative analysis on Clonorchis sinensis gene expression by real-time PCR. Parasitol. Res. 104: 321-328. http://dx.doi.org/10.1007/s00436-008-1195-x

Zhang MF, Jiang LM, Zhang DM and Jia GX (2015). De novo transcriptome characterization of Lilium 'Sorbonne' and key enzymes related to the flavonoid biosynthesis. Mol. Genet. Genomics 290: 399-412. http://dx.doi.org/10.1007/ $\underline{\mathrm{s} 00438-014-0919-0}$

Zhu X, Li X, Chen W, Chen J, et al. (2012). Evaluation of new reference genes in papaya for accurate transcript normalization under different experimental conditions. PLoS One 7: e44405. http://dx.doi.org/10.1371/journal. pone. 0044405 